\title{
O MEGAEVENTO DE LAZER COPA DO MUNDO FIFA BRASIL 2014 E A SUA RELAÇÃO EM UMA ESCOLA ESTADUAL DE BELO HORIZONTE - MG
}

Recebido em: 13/05/2014

Aceito em: 22/11/2014

\author{
Amarildo da Silva Araujo ${ }^{1}$ \\ Silvio Ricardo da Silva ${ }^{2}$ \\ Universidade Federal de Minas Gerais \\ Belo Horizonte - MG - Brasil
}

\begin{abstract}
RESUMO: A realização do megaevento da Copa do Mundo da FIFA Brasil 2014 trouxe mudanças nas cidades-sedes e produziu impactos em diversos campos como: economia, política, organização espacial, dentre outros campos da sociedade. A educação não ficou alheia a esse quadro, visto que a Copa atingiu as pessoas independente delas serem torcedoras ou não e também chegou às instituições escolares. Assim, este estudo teve como objetivo analisar a relação pedagógica entre $\mathrm{o}$ megaevento de lazer da Copa do Mundo FIFA Brasil 2014 e uma escola pública. Foi realizado o estudo de caso com a utilização da análise de documentos, questionário e entrevista. Os resultados mostraram que esse megaevento de lazer recebeu um tratamento secundário no campo da educação, constatando que o potencial educativo desse acontecimento foi pouco explorado no universo da educação escolar.
\end{abstract}

PALAVRAS CHAVE: Esportes. Educação. Atividades de Lazer.

\section{THE MEGAEVENTO LEISURE WORLD CUP FIFA BRAZIL 2014 AND YOUR RELATIONSHIP IN A STATE SCHOOL IN BELO HORIZONTE - MG}

ABSTRACT: The completion of the mega event of the FIFA World Cup Brazil 2014 brought changes in host cities and produced impacts in various fields such as economy, politics, spatial organization, among other fields of society. Education has not been blind to this situation, since the World Cup reached independent of them people being cheerleaders or not, and also reached the schools. Thus, this study aimed to analyze the pedagogical relationship between leisure mega event of the FIFA World Cup Brazil 2014 and a public school. The case study with the use of document analysis, questionnaire and interview was conducted. The results showed that this mega event leisure received secondary treatment in the field of education, noting that the educational potential of this event was unexplored in the world of education.

KEYWORDS: Sports. Education. Leisure Activities.

\footnotetext{
${ }^{1}$ Mestre em Estudos do Lazer pelo Programa de Pós Graduação Interdisciplinar em Estudos do Lazer da Universidade Federal de Minas Gerais.

${ }^{2}$ Professor da. Escola de Educação Física, Fisioterapia e Terapia Ocupacional da Universidade Federal de Minas Gerais. Coordenador do Grupo de Estudos sobre Futebol e Torcida - GEFuT.
} 


\section{Introdução}

O lazer como área de conhecimento multidisciplinar possibilita a pesquisa em diversas temáticas de estudo. Segundo Magnani (2000) a multidisciplinaridade é intrínseca ao objeto lazer e tem propiciado estudos com ênfases e orientações diferentes, destacando a importância de ter novos e amplos olhares sobre o tema. Nos últimos anos um dos assuntos que desperta o interesse da comunidade acadêmica brasileira é o futebol enquanto possibilidade de lazer, tanto que, de acordo com Silva, Souza Neto e Campos (2011, p.117), “o futebol enquanto tema de pesquisa já está consolidado", tendo diversos trabalhos desenvolvidos no campo das ciências humanas.

O futebol ultrapassa os limites das linhas do campo de jogo e constitui importante elemento de (con)vivência de lazer de muitos brasileiros. Reis (1998) afirma que a assistência aos espetáculos de futebol é a atividade de lazer esportivo com o maior número de adeptos no mundo. Campos (2010) reitera essa afirmação, ao afirmar que o futebol, para grande parte da população brasileira, é um referencial de lazer, tanto na possibilidade do jogo quanto da assistência, manifestando-se, por isso, como uma linguagem dessa sociedade.

O futebol é um fenômeno sociocultural que se tornou um símbolo de identidade nacional. Considerando que ele pode ser visto com diferentes olhares a complexidade e a dimensão da realização de um megaevento como a Copa do Mundo da FIFA Brasil 2014 produzem impactos na vida das pessoas, independentemente de elas serem torcedoras ou não, além disso, atingiram diversas instituições escolares.

Segundo Libâneo, Oliveira e Toschi (2008, p. 52), os acontecimentos contemporâneos (dentre eles, ressalto a Copa do Mundo da FIFA Brasil 2014) afetam a educação escolar de várias maneiras, a saber: modificam objetivos e prioridades da escola; produzem alterações nos interesses, nas necessidades e nos valores escolares; 
forçam a escola a mudar suas práticas; e induzem a transformações na atitude do professor e no trabalho docente. Libâneo, Oliveira e Toschi (op. cit.) procuram mostrar que os conhecimentos advindos das produções socioculturais que se originam fora da escola interferir, de alguma maneira, nas práticas escolares.

Ao refletirmos sobre a relação futebol, Copa do Mundo da FIFA Brasil 2014, escola e lazer, surgiu a seguinte questão: como o megaevento da Copa do Mundo da FIFA Brasil 2014 foi tratado na escola? Na tentativa de contribuir com a discussão sobre essa temática fizemos uma pesquisa em Belo Horizonte analisou como o megaevento de lazer da Copa do Mundo da FIFA Brasil 2014 foi tratado em uma escola pública de Belo Horizonte - MG.

Entendemos que negligenciar a existência de vínculos reais e/ou potenciais, nesse sentido, pode conduzir a uma interpretação que desqualifica a escola como local onde não se discutem questões que afetam o cotidiano da sociedade ou onde não se atribui a elas a devida e/ou merecida importância.

A propósito dessa questão, Bracht e Almeida (2013) afirmam que na relação megaeventos esportivos e escola, existem zonas de conflito dos códigos e princípios do modelo dominante de esporte com os da instituição escolar. Sem se render à lógica do sistema esportivo, a escola deve voltar o esporte aos objetivos educacionais, visando promover ampla "alfabetização esportiva" da população. Justificando a lógica do sistema esportivo que predomina fora da escola, Bracht e Almeida (2013) consideram que a Copa do Mundo da FIFA Brasil 2014 apresenta risco renovado de se instrumentalizar o esporte na escola; ou seja: reproduzir, nela, seu formato baseado no rendimento esportivo e na competição.

Madruga (2008) defende a realização dos megaeventos com amparo na ideia de relação custo/oportunidade. Esse binômio voltado para a escola pode ser utilizado com 
o que estamos chamando de educação/oportunidade; ou seja: a escola busca se envolver com esse momento histórico e social que a população e o País estão/estavam viven(cian)do e, por meio de ações pedagógicos extrai desse megaevento o máximo de possibilidades educativas. Nessa perspectiva, Candau (2007, p.13) afirma que:

[...] os processos educativos se desenvolvem a partir de diferentes configurações. A pluralidade de espaços, tempos e linguagens devem ser não somente reconhecidas, como promovidas. A educação não pode ser enquadrada numa lógica unidimensional aprisionada numa institucionalização específica.

Logo, concordando com essa autora, acreditamos que o processo educativo dialoga com outras esferas, como os megaeventos e seus impactos produzidos, por exemplo. A Copa do Mundo da FIFA Brasil 2014 foi uma entre outras possibilidades de vivência do lazer e de oportunidade para o ambiente escolar refletir sobre essas questões; além disso, desenvolver saberes que sejam significativos para o estudante, para o professor e para a escola.

\section{Metodologia}

Nessa investigação, de abordagem qualitativa, foi realizado o estudo de caso em uma escola da rede pública estadual do município de Belo Horizonte. A escolha da instituição ocorreu através de sorteio. Optamos por investigar um professor por disciplina do ensino médio nos turnos da manhã e noite. Participaram 23 (vinte e três) docentes, sendo 12 (doze) pelo turno da manhã e noite 11 (onze) para a noite, preferencialmente os atuantes com os terceiros anos. A diferença quanto ao número de docentes é devido à professora de artes ministrar a sua disciplina nos 2 (dois) turnos da escola que foram investigados.

A coleta dos dados ocorreu nas dependências da escola em duas etapas. $\mathrm{Na}$ primeira, foi realizada a entrevista semiestruturada em novembro e dezembro de 2013 e 
na segunda, aplicamos os questionários em março de 2014. Esse procedimento permitiu comparar as realizações desenvolvidas e as intenções em 2013 com as intenções de realizar as atividades ou projetos de educação relativos ao ano de 2014. A coleta de dados ocorreu nas dependências da escola. Todos os sujeitos participaram do estudo voluntariamente e receberam as explicações dos motivos que os levaram a serem convidados, fizeram a leitura e assinaram o Termo de Consentimento Livre e Esclarecido $^{3}$ - TCLE.

Os caminhos percorridos foram os seguintes: 1) revisão bibliográfica para fundamentação teórica sobre o megaevento da Copa do Mundo da FIFA Brasil 2014, o lazer e a educação; 2) pesquisa documental, com ênfase na educação escolar e no lazer, realizada nos dados oficiais apresentados pelos organizadores da Copa do Mundo da FIFA Brasil 2014 e nos registros escolares; e 3) pesquisa de campo com os (as) professores (as).

\section{Fundamentação Teórica: O megaevento da Copa do Mundo da FIFA Brasil 2014,}

\section{o lazer e a educação}

Algumas cidades buscam, na organização dos megaeventos, a possibilidade de se promoverem mundialmente e de impulsionar em seu desenvolvimento urbano. Assim, a tarefa de sediar uma empreitada como a Copa do Mundo da FIFA Brasil 2014 surgiu como uma alternativa para acelerar a construção de planos de (re) estruturação da cidade e, como consequência, melhorar a qualidade de vida da população (PIRES; BAPTISTA; PORTUGAL, 2013).

\footnotetext{
3 Termo de Consentimento Livre e esclarecido - TCLE é a anuência do sujeito da pesquisa e/ou de seu representante legal, livre de vícios (simulação, fraude ou erro), dependência, subordinação ou intimidação, após explicação completa e pormenorizada sobre a natureza da pesquisa, seus objetivos, métodos, benefícios previstos, potenciais riscos e o incômodo que esta possa acarretar, formulada em um termo de consentimento, autorizando a participação voluntária na pesquisa.
} 
Dessa forma, a escolha de um país para sediar um megaevento requer, de modo geral, o aporte de vultosos recursos econômicos, além dos montantes usuais nos orçamentos públicos, e a capacidade de negociação, em diferentes esferas do poder público, para atender os pré-requisitos desse evento.

Vale lembrar, que no Brasil não houve consenso a respeito da forma como ocorreu o processo de organização da Copa do Mundo da FIFA Brasil 2014. Existiram os apoiadores do evento como os governos e grupos empresariais envolvidos com a realização da Copa, as construtoras que empreitam as obras, a cadeia do setor do turismo, a grande imprensa e outros. Quanto à população, a pesquisa ${ }^{4}$ realizada pelo Instituto Data Folha mostrou que a taxa de apoio da população à realização do evento no País em novembro de 2008 foi de $79 \%$ (setenta e nove) e em junho de 2013 foi de $65 \%$ (sessenta e cinco) dos brasileiros. Também houve os contrários ${ }^{5}$ como, por exemplo, a Articulação Nacional dos Comitês Populares, ${ }^{6}$ organizados nas 12 (doze) cidades-sedes, alguns grupos de intelectuais ligados à academia, partidos políticos de orientação à extrema esquerda e associações ligadas a movimentos populares de grupos atingidos pela Copa. Entre essas posições antagônicas há aquelas intermediárias que buscam se afastar da polarização, nessa discussão, como exemplo parte da academia e da mídia.

\footnotetext{
4 Dados extraídos do Instituto de Pesquisas Data Folha. Copa do Mundo PO 813747 03 a 05/06/2014. Essa pesquisa está registrada no Tribunal Superior Eleitoral com o número - BR00144/2014. Disponível em: http://media.folha.uol.com.br/datafolha/2014/06/10/copa-do-mundo-versaopara-o-site.pdf acesso em 01/Ago./2014.

5 A ideia de contrários (críticos) pode ser entendida de diversas maneiras; aqui, são baseadas em duas: os contrários que reprovam o modo como tem sido conduzido o processo para realização da Copa 2014 e desejam que o evento ocorra no Brasil e os contrários que se posicionam contra a ocorrência desse megaevento no país, entre alguns dos motivos estão às exigências prévias feitas pela FIFA para com o país-sede como as concessões, construções e ingerências na legislação.

${ }^{6}$ No Rio de Janeiro, o Comitê Popular Rio Copa e Olimpíadas é um exemplo desse grupo que está organizado a partir da participação e mobilização de um conjunto de entidades, movimentos e lideranças - Associação dos Geógrafos Brasileiros - AGB, CORECON-RJ, CMP, Conselho Popular, ETTERN IPPUR/UFRJ, FAM Rio, FASE Rio de Janeiro, Frente Nacional dos Torcedores, IBASE, MNLM, MTST, MUCA, Núcleo Frei Tito, Ocupação Quilombo das Guerreiras, PACS, Redes da Maré, Reunindo Retalhos, Universitários da UFRJ, Vila_Autódramo e Observatório das Metrópoles. Disponível em: <http://blogdomasca.blogspot.com.br/2013/01/copa-praquem.html>. Acesso em: 12 mar. 2014.
} 
De acordo com Ratton (2012) os megaeventos apresentam duas características centrais: as consequências trazidas para as cidades, regiões ou países e a atração da cobertura midiática que eles geram. Esses megaeventos ocorrem em intervalos temporais maiores do que campeonatos e ligas esportivas habituais, apresentando estrutura e programação de grande porte, bem acima da média dos eventos esportivos nacionais ordinários. Também contam com os meios de comunicação de massa, em suas mais variadas formas, para potencializar a magnitude de um megaevento.

Rubio (2005) afirma que um megaevento se caracteriza por seu caráter temporal, sua capacidade de atrair um grande número de participantes de diversas nacionalidades e, também, por chamar a atenção dos meios de comunicação, com abrangência e ressonância global. A propósito da sazonalidade dos megaeventos esportivos, Machado e Rubio (2013, p.70) afirmam que "são eventos de curto prazo, com duração variável de duas semanas a um mês, com consequência de longo prazo para a localidade que os abriga". Destacam, ainda, a exibição das cidades na mídia, durante seu período de realização, de uma forma que jamais conseguiriam atingir. Observa-se, assim, uma aproximação entre o pensamento de Ratton (2012) e o de Machado e Rubio (2013), no que diz respeito ao entendimento sobre megaevento esportivo.

Marcellino (2013) considera que os megaeventos não se limitam aos esportivos, eles envolvem uma variada gama de expressões culturais. Aborda os megaeventos sobre a perspectiva do lazer. Esse autor entende que eles representam para quase toda a população, atividades de lazer que contemplam, prioritariamente, os conteúdos físicos esportivos, sociais e turísticos.

Bracht (2003) adota o lazer inserido na ideia de cultura proposta por Forquin (1993, p.13), “a responsabilidade de ter que transmitir e perpetuar a experiência considerada cultura, o que justifica fundamentalmente o empreendimento educativo. A 
cultura é o conteúdo substancial da educação". Dessa forma, operar com a noção de cultura que não separa o lazer do trabalho e da produção da vida, possibilita pensar a educação além de uma perspectiva instrumental.

Destacamos dois aspectos levantados por Bracht (2003) como fundamentais na relação entre lazer e educação. $\mathrm{O}$ crescimento do consumo de produtos e serviços de lazer tornou-se aliado do desenvolvimento tecnológico e a facilidade de (re) produção dos bens simbólicos. No entanto, não é qualquer consumo e nem qualquer prazer. É aquele que pela via do consumo o prazer adquire status na nossa sociedade, ou seja, há um reconhecimento legitimado pela nossa cultura pela busca do prazer no lazer, via consumo. Se por um lado existe a educação, por outro há a sedução pelo prazer. Uma sociedade baseada numa economia de mercado tende a priorizar o mecanismo da sedução em detrimento da educação para orientar as ações dos consumidores.

Nessa direção, Mascarenhas (2007, p.2) contribui afirmando que:

[...] observa-se no Brasil, a pouco mais de uma década, uma tendência de expansão acelerada dos negócios envolvendo o lazer, com a proliferação de novas e diversas práticas de divertimento entre a população. Neste cenário, subordinado à forma mercadoria, o lazer esvazia-se cada vez mais de conteúdo verdadeiramente humanizante. Preso à lógica do consumo estimula o prazer e o gozo imediatos. O caráter social e educativo dos antigos lazeres, ainda que atrelado a interesses físico e morais de produção e reprodução da força do trabalho, sucumbe mais e mais ao colorido e ao êxtase dos serviços de diversão disponíveis no mercado.

Concordamos com a preocupação dos autores em levantar essa discussão que envolve o mercado, pensamos que essa tríade lazer, educação e consumo é um tema central na formação dos estudantes pela escola que requer a orientação dos consumidores, em especial, os alunos como um papel da educação.

O segundo aspecto aborda o lazer na perspectiva cultural com a ampliação do seu espaço na escola. De acordo com Bracht (2003) as diferentes disciplinas da escola devem contribuir para a educação para o lazer. Porém, de acordo com a organização dos conhecimentos e práticas escolares a Educação Física e a Educação Artística são mais 
próximas ou diretas com o lazer, pois educam para ele ao transmitir suas práticas que podem ser vivenciadas nessa dimensão da vida.

Bracht (2003, p.164) defende a ideia que:

[...] não devemos responsabilizar exclusivamente uma ou outra disciplina escolar pela a educação para o lazer (a Educação Física e a Educação Artística por exemplo), mas que a escola como um todo, deve assumir a educação para o lazer como tarefa nobre e importante, o que implica em colocar em questão as próprias finalidades sociais da instituição escolar. Isso implicaria em uma razoável mudança naquilo que poderíamos chamar de cultura escolar que, diga-se logo, não envolve apenas os saberes e as práticas escolares, mas também, o tempo e o espaço.

Assim, concordamos com Bracht (2003) ao afirmar que a educação para o lazer não é tarefa de uma ou outra disciplina escolar, demonstrando o caráter multidisciplinar do lazer nas disciplinas curriculares. Tendo em vista as diferentes áreas que se relacionam com esse objeto de estudo e intervenção, é fundamental pensar em possibilidades coletivas para superar a ideia de que esse campo cabe somente a essa ou aquela área. Isayama (2010) considera que a multidisciplinaridade contribui de forma substancial para avanços qualitativos sobre o lazer. Os olhares múltiplos devem ser considerados e analisados, pois podem fomentar a reflexão e a crítica, apontando diferentes abordagens e questionamentos, dessa forma, colaborando para o debate e o aprofundamento de conhecimentos sobre o tema.

Considerando a Copa do Mundo da FIFA Brasil 2014 como um evento de lazer, que demonstra o caráter intercultural do futebol ela possibilita pensar no âmbito escolar a transversalidade conforme afirma Betti (2009, p.25):

[...] essa transversalidade do futebol, esporte com presença marcante na cultura brasileira e agenda obrigatória das mídias, pode ser pensada para outras disciplinas escolares. Por exemplo, a Copa do Mundo, pela popularidade que alcança no Brasil, pode ser uma oportunidade privilegiada, do ponto de vista didático-pedagógico, para a abordagem inicial de muitos temas/conteúdos: geografia (continentes e países); filosofia (ética e fair play); biologia (fisiologia do exercício físico); física (velocidade/aceleração); língua portuguesa (texto jornalístico). E, evidentemente, a Educação Física escolar: táticas e sistemas de jogo, regras oficiais. 
Para Nicácio (2012) o futebol é um fenômeno sociocultural que pode ser transmitido a partir do lazer. No cotidiano da escola ele se manifesta ou se reproduz independente das práticas de ensino. Como conteúdo de disciplina escolar, especificamente, da Educação Física, o futebol não deve ser concebido somente na perspectiva da prática, ou seja, do jogo em si. Pode também ser visto de uma forma engajada com o torcer. Portanto, a inserção no meio futebolístico não se torna dependente somente da prática em si, mas ampliam-se as formas de envolvimento dos indivíduos com esse esporte, disseminando e fortalecendo as relações que permeiam a sociedade.

Silva e Campos (2014) entendem que o futebol não se limita ao esporte institucionalizado por federações, com um conjunto de regras e normatizações para o seu funcionamento, ele supera esses elementos, uma vez que faz conexões históricas com temas e dilemas sociais, levando a inferir que deveria estar presente de maneira reflexiva no cotidiano escolar, sobretudo nas aulas de Educação Física. Mas, para esses autores essa situação não ocorre na grande maioria das escolas, em virtude ao entendimento do que venha a ser a disciplina curricular Educação Física e o conteúdo do futebol nessa cadeira, cabendo à Educação Física o papel de fundamentalmente problematizar as manifestações corporais presentes no cotidiano dos alunos. Afirmam que essa tarefa poderia ser ampliada ao conjunto das disciplinas escolares dentro de suas especificidades. Contudo, a escola ainda não compreende o futebol em perspectiva mais ampla, como uma possibilidade de educação e de formação para a vida social (SILVA; CAMPOS, 2014).

Esses autores reiteram a vivência prática que deve ser dada a esse conteúdo, porém acrescentam a inserção da perspectiva das ciências humanas nas atividades pedagógicas. Afirmam ser um equivoco passar pela educação básica considerando-o 
apenas como um jogo, desprovido de maiores reflexões, apresentam alternativas de espaços e formas de manifestação dessa prática ao entenderem que outros ambientes dentro na escola e fora constituem locais que possibilitam a aplicação de diferentes metodologias como biblioteca, sala de aula, sala de informática, visitas à museus, estádios, clubes, áreas públicas onde realizam essa prática, federações, dentre outras.

Silva (2013) aborda a Educação Física escolar relacionada aos legados de megaeventos esportivos, com destaque para possíveis aspectos positivos e negativos que poderão refletir nessa disciplina. Para a autora, os megaeventos são uma oportunidade de realizar essa discussão em conjunto com a academia. As escolas e os governos devem criar oportunidade para os professores de Educação Física terem acesso aos novos conhecimentos produzidos na área e manter um processo contínuo de formação, gerando mais chances de construção de projeto escolar comprometido com a emancipação dos estudantes.

Daólio (2013) se preocupa com a maneira como tem ocorrido a concepção e organização dos megaeventos esportivos no País, para esse autor existe o risco de gerar pessoas passivas que apenas consumam os espetáculos esportivos e os produtos a eles associados predominando o consumismo, sem possibilidade de maiores conhecimentos e, sobretudo, de prática. Chama a atenção para o papel do professor que deve assumir esse trabalho de esclarecimento com os estudantes. Daólio (2013, p.135) afirma que:

[...] a tarefa urgente e fundamental da Educação Física escolar: diante do fato de que os megaeventos esportivos estão mesmo acontecendo, os professores da área devem assumir esse tema em suas aulas, não no sentido de reproduzir o ufanismo acrítico propalado pela mídia, mas de estimular junto aos alunos um conhecimento crítico que leve à prática esportiva consciente e transformadora. Como mediadores pedagógicos que são, os professores de Educação Física atualizam significados junto com seus alunos, desconstroem visões de senso comum e reconstroem e ampliam outras formas de compreensão em relação aos conteúdos da área. Nesse sentido é possível esperar que, a partir da mediação da Educação Física escolar, a compreensão e a relação dos alunos com os megaeventos esportivos serão qualificadas. 
Dessa forma, entendemos que a postura pedagógica assumida pelos professores de Educação Física irá contribuir para qualificar a compreensão dos alunos sobre os megaeventos esportivos. Não intervir de forma crítica pode reforçar ações que mantenham a hegemonia do esporte de rendimento na escola.

\section{Pesquisa documental: os documentos vinculados aos órgãos oficiais e suas interfaces com a pesquisa de campo}

A análise documental recebeu ênfase na educação escolar e no lazer, sendo realizada nos documentos que tratavam dos dados oficiais apresentados pelos organizadores da Copa do Mundo da FIFA Brasil 2014 e nos registros escolares.

Foi investigada a Lei Geral da Copa - LGC (BRASIL, 2012), publicada, pela Câmara dos Deputados e os seus desdobramentos no site do Ministério da Educação MEC, da Secretaria de Estado de Educação - SEE-MG e da Secretaria Municipal de Educação de Belo Horizonte - SMED.

Na escola foi pesquisado o seu Projeto Político Pedagógico - PPP e quanto aos planos de curso das disciplinas que seriam importantes investigarem para verificar os projetos educacionais relacionados à Copa do Mundo da FIFA Brasil 2014 não foi possível o acesso.

As principais fontes de dados desta pesquisa foram os sites institucionais desses órgãos, por reunirem informações oficiais sobre as proposições dessas instituições quanto à realização da Copa do Mundo da FIFA Brasil 2014 e ao funcionamento das escolas durante esse acontecimento. Outros encaminhamentos para esse estudo foram as notícias expedidas pelos órgãos oficiais de comunicação institucional dos entes governamentais que concernem às orientações dadas para instituições escolares em âmbito estadual. 
No Brasil, a responsabilidade com relação a FIFA coube ao Governo Federal, que agilizou os trâmites relacionados à organização da Copa do Mundo da FIFA Brasil 2014, o que significou rapidez para aprovar medidas que garantissem os interesses da realização do evento para a FIFA e a União.

De acordo com a LGC (BRASIL, 2012, p. 7), “em 2007, o governo brasileiro demonstrou seu apoio ao evento que necessitou da elaboração de uma legislação especifica". A Lei $\mathrm{n}^{\mathrm{o}} 12.663$, de 5 de junho de 2012. Nesse documento foi analisado a educação e o lazer, constatamos que o seu desdobramento atingiu a educação nos âmbitos federal, estadual e municipal, no entanto, a LGC (BRASIL, 2012) fez uma única referência à educação escolar, no seu no art. 64, qual seja:

[...] art. 64. Em 2014, os sistemas de ensino deverão ajustar os calendários escolares de forma que as férias escolares decorrentes do encerramento das atividades letivas do primeiro semestre do ano, nos estabelecimentos de ensino das redes pública e privada, abranjam todo o período entre a abertura e o encerramento da Copa do Mundo FIFA 2014 de Futebol.

No que diz respeito à Secretaria de Estado de Educação de Minas Gerais, a Resolução SEE-MG nº 2.368 (MINAS GERAIS, 2013) não fez menção alguma à Copa do Mundo da FIFA Brasil 2014. Estabelece, porém, como "recesso escolar comum”, os dias referentes ao período previsto para a Copa do Mundo, apresentando um alinhamento com a LGC.

A determinação dos 30 (trinta) dias de recesso escolar entre a abertura e o encerramento da Copa do Mundo FIFA Brasil 2014, descrito na LGC (BRASIL, 2012) não infringiu a legislação, embora pareça uma decisão arbitrária para a educação nacional, em função de essa alteração atender interesses de uma empresa particular, a FIFA, para a realização de seu evento.

A Lei de Diretrizes e Bases LDB (BRASIL, 1996), quando propôs a flexibilidade do calendário escolar, certamente considerou as atividades de ciclos 
produtivos que não coincidem com o ano civil e não o ajuste para adequar milhares de pessoas a um interesse de uma empresa particular estrangeira. Entendemos que a abertura acertada na citada lei acabou sendo enrijecida pelos governos federal, estadual e municipal e se transformou em modelo único, levando a educação a um estado de subserviência face às exigências do evento.

Apontamos que o tema da educação escolar, nos documentos analisados relacionados à Copa do Mundo da FIFA Brasil 2014, gerou desdobramentos que atingiram o sistema de ensino brasileiro. Essa matéria aparece como periférica e secundária na LGC (2012), porque as atribuições e referências no que tange à educação, nesses registros, são direcionadas única e exclusivamente aos ajustes do calendário escolar durante o período da competição.

No que diz respeito ao termo "lazer" foi localizado uma única vez na LGC (BRASIL, 2012), no seu art. $2^{\circ}$, inciso XIV, que aparece a seguir:

[...] art. $2^{\circ}$ Para os fins desta lei serão observadas as seguintes definições: XIV - locais oficiais de competição: locais oficialmente relacionados às competições, tais como estádios, centros de treinamento, centros de mídia, centros de credenciamento, áreas de estacionamento, áreas para a transmissão de partidas, áreas oficialmente designadas para atividades de lazer destinadas aos fãs, localizados ou não nas cidades que irão sediar as competições, bem como qualquer local no qual o acesso seja restrito aos portadores de credenciais emitidas pela Fifa ou de ingressos (grifo nosso).

A LGC (BRASIL, 2012) insere o lazer nos "locais oficiais de competição", nas "áreas oficialmente designadas para atividades de lazer destinadas aos fãs", relacionando-o apenas a um conceito espacial, de forma genérica.

Concordamos com Marcellino (2010, p.66), ao afirmar que o lazer não deve ser convertido em "mercadoria vendida no mercado do entretenimento" e também a "prática de uma atividade". Com base no $2^{\circ}$ inciso XIV da LGC (BRASIL, 2012), o lazer é considerado mera atividade, destinada para os fãs do Futebol, nesse caso, 
reservando-lhes áreas oficialmente designadas, remetendo-nos a uma abordagem funcionalista.

Esse tratamento dado ao lazer restringe o seu entendimento às áreas reservadas aos fãs, inclusive não inserindo os estádios, claramente, como locais de lazer e, sim, como de "locais oficiais de competição", deixando de considerar o tempo, o espaço, a atitude, as atividades, a subjetividade, o comportamento e outros elementos vinculados ao esporte e aos cidadãos que estão intrinsecamente relacionados ao lazer.

Bracht (2003) menciona que o lazer direcionado somente pelo prazer estimula o consumo exacerbado em uma sociedade onde o mercado dita as normas, afirmando que a escola torna-se um espaço fundamental para discussão dessa relação. Sobre essa questão concordamos com Bracht (2003) e também com Mascarenhas (2007) ao considerar que, cada vez mais, o lazer está subordinado à forma de mercadoria, sob o comando de grupos hegemônicos que não têm a preocupação e o compromisso com o caráter humanizante do lazer. Nessa lógica entendemos que não é mais o produto que se põe a servir o consumidor é o cliente que é consumido pela mercadoria, pois a força do mercado que distingue o status que passa a ter um papel direcionador nessas relações.

Em visita ao portal da SEE-MG ${ }^{7}$ com o intuito de buscar outros documentos relativos à Copa 2014, além do calendário escolar, foi encontrado o projeto "IV Simpósio de Esporte na Escola" é uma realização do Conselho Regional de Educação Física em parceria com a Secretaria de Estado de Educação. A edição de 2014 tem como temática o ensino do futebol na escola. Segundo o site "em ano de Copa do Mundo, o simpósio destaca boas práticas relacionadas ao futebol nas escolas" essa fonte também nos diz que "as boas práticas na área esportiva desenvolvidas nas escolas mineiras podem ganhar visibilidade no ano da Copa do Mundo do Brasil”. Esse

7 Disponível em: http://www.educacao.mg.gov.br/component/gmg/story/5906-em-ano-de-copa-domundo-simposio-destaca-boas-praticas-relacionadas-ao-futebol-nas-escolas Acesso em 10/Mar/2014. 
Simpósio foi desenvolvido no período de novembro de 2013 a agosto de 2014 em 47 Superintendências Regionais de Ensino, oferecendo premiações em espécie para os 3 (três) primeiros colocados em cada categoria.

Do ponto de vista institucional, percebeu-se que o projeto supracitado constituiuse na proposta pedagógica da SEE-MG referente à Copa do Mundo da FIFA Brasil 2014. Ele envolve esse tema da apenas na disciplina de Educação Física, não contemplando outras matérias da matriz curricular. Em suas etapas esse documento menciona atividades práticas de futebol, no entanto, não faz alusão nenhuma referente à Copa do Mundo da FIFA Brasil 2014. Identificamos que o "Simpósio de Esporte na Escola" está em sua quarta edição e apenas associou a tema Copa do Mundo da FIFA Brasil 2014 em sua proposta de ação, no entanto, esse megaevento não ocupa o centro da proposta, pois, trata-se de práticas de futebol sem exigências de relacioná-las a esse megaevento de lazer.

Diferente do que apresentou a SEE-MG, concordamos com Betti (2009) ao entender que o futebol é potencializado pela Copa do Mundo da FIFA 2014 com ampla possibilidade de desenvolvimento de projetos pedagógicos, favorecido pelo caráter intercultural característico desse esporte no momento desse megaevento.

No site da SEE-MG, após a busca pela palavra copa, no ícone "Notícias" foram encontradas três notas de escolas que estão desenvolvendo ou desenvolveram projetos sobre o megaevento de 2014. Esses projetos são desenvolvidos pelas unidades escolares, não sendo um encaminhamento da própria SEE-MG. Portanto, é possível perceber que a SEE-MG oferece apoio a esses trabalhos a partir da divulgação dos mesmos no seu site. No entanto, a iniciativa de realização de tais trabalhos não é parte de uma diretriz da SEE-MG. Dessa forma, concluímos que a SEE-MG não estabeleceu 
uma diretriz para as unidades escolares com vistas a tratar a Copa do Mundo da FIFA 2014 pedagogicamente.

Quanto aos documentos da escola, foi disponibilizado para análise, o Projeto Político Pedagógico - PPP elaborado em 2010. Nesse documento, não foi encontrada proposta alguma de intervenção pedagógica em acontecimentos ou episódios de grande repercussão midiática envolvendo a sociedade ou fato diretamente voltado à educação, nesse sentido. Também não houve nenhuma diretriz por pela parte diretiva da escola em 2013 para desenvolver atividades referentes ao evento. Portanto, os acontecimentos que de alguma forma ocorrem fora dos limites físicos da escola e tiveram ampla repercussão na sociedade não figuram como interesse desse documento para possíveis intervenções pedagógicas. Quanto os planos de curso não foram disponibilizados.

A luz dos documentos analisados foi possível constatar que a Copa do Mundo da FIFA Brasil 2014 para os organizadores não foi explorada pedagogicamente, diferente do que sugerem Silva (2013) e Betti (2009), demonstrando diferentes possibilidades de intervenção pedagógica. Segundo os documentos demonstram os organizadores não se envolveram com o possível potencial educativo da Copa do Mundo da FIFA 2014.

\section{Pesquisa de campo com os professores}

Em 2013, foi pesquisado se os docentes desenvolveram algum projeto ou atividade relacionada ao megaevento. 
Tabela 1 - Atividade pedagógica relativa à Copa - professores - 2013

\begin{tabular}{|c|c|}
\hline Manhã/ Química. & $\begin{array}{l}\text { Não tem nenhum projeto e nem pensou em } \\
\text { desenvolver. }\end{array}$ \\
\hline Manhã/ Biologia. & Não; no ano de 2014, sim. \\
\hline Manhã/ História. & Não em 2013 e sim ano de 2014 \\
\hline Manhã/Noite. Artes. & Não; os outros professores já trabalham. \\
\hline Manhã/Matemática. & Não, não pensou. \\
\hline Manhã/ Português. & Não, mas gostaria. O foco é o Enem. \\
\hline Manhã/ Inglês. & Sim, já desenvolveu em Copas anteriores. \\
\hline Manhã/ Física. & Não pretendeu trabalhar. \\
\hline Noite/ Sociologia. & $\begin{array}{l}\text { Sim, as manifestações na Copa das } \\
\text { Confederações. }\end{array}$ \\
\hline Noite/ Inglês. & Sim, mural de pontos turísticos. \\
\hline Noite/ Filosofia. & Não pretendeu trabalhar. \\
\hline Manhã/ Educação Física. & Sim, jogos. \\
\hline Manhã/Geografia. & Não, o foco é o Enem. \\
\hline Manhã/ Filosofia. & $\begin{array}{l}\text { Não, mas não tem como ficar fora em } \\
\text { 2014. }\end{array}$ \\
\hline Noite/ História. & Não desenvolveu. \\
\hline Manhã/ Sociologia. & Não especificamente e sim oportunamente. \\
\hline Noites/ Português. & Não, o foco é o Enem. \\
\hline Noite/ Geografia. & $\begin{array}{l}\text { Sim, na Copa das Confederações. } \\
\text { Comparação dos índices do Brasil com os } \\
\text { países participantes desse evento. }\end{array}$ \\
\hline Noite/Química. & Sim, textualmente a questão do doping. \\
\hline Noite/ Biologia. & Não desenvolveu. \\
\hline Noite/ Física. & $\begin{array}{l}\text { Sim, indiretamente. Discutindo a } \\
\text { experiência sobre ser voluntário na Copa } \\
\text { das confederações. }\end{array}$ \\
\hline Noite/ Matemática. & Não, mas pretende. \\
\hline Noites/ Educação Física. & Sim, campeonato. \\
\hline
\end{tabular}

Fonte: Autores da pesquisa 
Verificamos que dos professores que afirmaram ter desenvolvido alguma atividade sobre o megaevento, não documentaram os trabalhos, ou seja, não houve o registro como um projeto pedagógico ou uma formalização escrita sobre o que foi trabalhado na disciplina.

Em linhas gerais os professores que trabalharam a temática da Copa abordaram o tema sem um direcionamento que buscasse um objetivo coletivo dos docentes e aqueles que não trabalharam destacaram que foi devido ao foco no Enem - Exame Nacional do Ensino Médio, não pensaram no assunto e não pretendem desenvolver esse tema com os estudantes.

Quanto ao Enem quatro dos que sete professores que não pretendiam fazer projetos referentes à Copa alegaram que é o foco do seu trabalho está voltado para essa avaliação. O objetivo desse exame é avaliar o desempenho (competências e habilidades) do estudante ao fim escolaridade básica. De modo geral os estudantes dos terceiros anos do ensino médio tem recebido uma atenção especial na preparação para essa avaliação, que é obrigatória para o ingresso dos estudantes nos cursos de graduação das universidades públicas federais e algumas instituições de ensino superior conveniadas com o Governo da União. As provas abordam questões de ordem mais abrangentes, inclusive, no que diz respeito ao lazer e, por conseguinte, podem abordar a temática da Copa do Mundo da FIFA Brasil 2014.

Tabela 2 - Atividades relativas à Copa - consulta em 2013

\begin{tabular}{|l|c|c|}
\hline \multicolumn{1}{|c|}{ Categorias } & $\mathrm{N}^{\mathrm{o}}$ de entrevistas & $\%$ \\
\hline 1- Desenvolveu (em 2013) & 7 & 30,43 \\
\hline $\begin{array}{l}\text { 2-Não desenvolveu, mas } \\
\text { pretendiam desenvolver (em } \\
\text { 2014). }\end{array}$ & 9 & 39,13 \\
\hline $\begin{array}{l}\text { 3- Não desenvolveu e não } \\
\text { pensou no assunto. }\end{array}$ & 3 & 13,04 \\
\hline $\begin{array}{l}\text { 4- Não desenvolveu e não } \\
\text { pretende desenvolver. }\end{array}$ & 4 & 17,39 \\
\hline
\end{tabular}

Fonte: Autores da pesquisa 
A princípio, dois grupos foram pensados: os que desenvolveram alguma atividade em 2013, grupo 1, e aqueles que não desenvolveram, grupo 2. No entanto, dentro do grupo 2, os que não desenvolveram nenhuma atividade relacionada à Copa do Mundo, foi possível distinguir outros três grupos distintos, formando, portanto, grupo 2, não desenvolveu atividade relacionada à Copa, mas pretendiam desenvolver em 2014; grupo 3, não desenvolveu atividade relacionada à Copa e não pensou no assunto e, grupo 4, não desenvolveu nenhum trabalho sobre a Copa e não pretendiam desenvolver em 2014.

Ao analisar o Quadro 2, foi verificado que próximo a um terço dos professores, 30,43\%, realizaram alguma atividade pedagógica tendo a Copa do Mundo da FIFA Brasil 2014 como referência. Os dados mostraram que 39,13\% dos docentes não trabalharam com essa temática, mas pretendiam desenvolver algum projeto em 2014. Há uma categoria que não pensou no tema da Copa para ser transformado em projeto de educação que somam $13,04 \%$ e, por fim, não pretendiam incluir esse tema em suas aulas $17,39 \%$ dos professores.

Sendo assim, se somadas os percentuais da categoria $1(30,43 \%)$ professores que desenvolveram alguma atividade em 2013 com a categoria $2(39,13 \%)$ os docentes que pretendiam trabalhar o tema da Copa no ano de 2014, são 69,56\% dos professores.

Vale ressaltar que, tanto em 2013, quanto em 2014 esse estudo propôs saber se o corpo docente desenvolveu ou teve a pretensão de efetivamente desenvolver alguma atividade ou projeto para o megaevento da Copa do Mundo da FIFA Brasil 2014, Porém não sendo possível identificar o registro do projeto de ensino dos professores, bem como a carga horária, o número de aulas, a profundidade de interação dos alunos com o tema e a implicação de projetos dessa natureza no contexto escolar e social, devido à ausência de formalização dos mesmos. Assim utilizamos o vocábulo intenção. 
Ao perguntar ao professor sobre qual a contribuição da sua disciplina para transformar a Copa do Mundo da FIFA 2014 em projeto de educação, a resposta obtida mostrou que todos os professores apresentaram pelo menos exemplos de como esse tema poderia ser tratado em sua disciplina.

Tabela 3 - Sugestões dos professores sobre trabalhos relativos à Copa - consulta em 2013

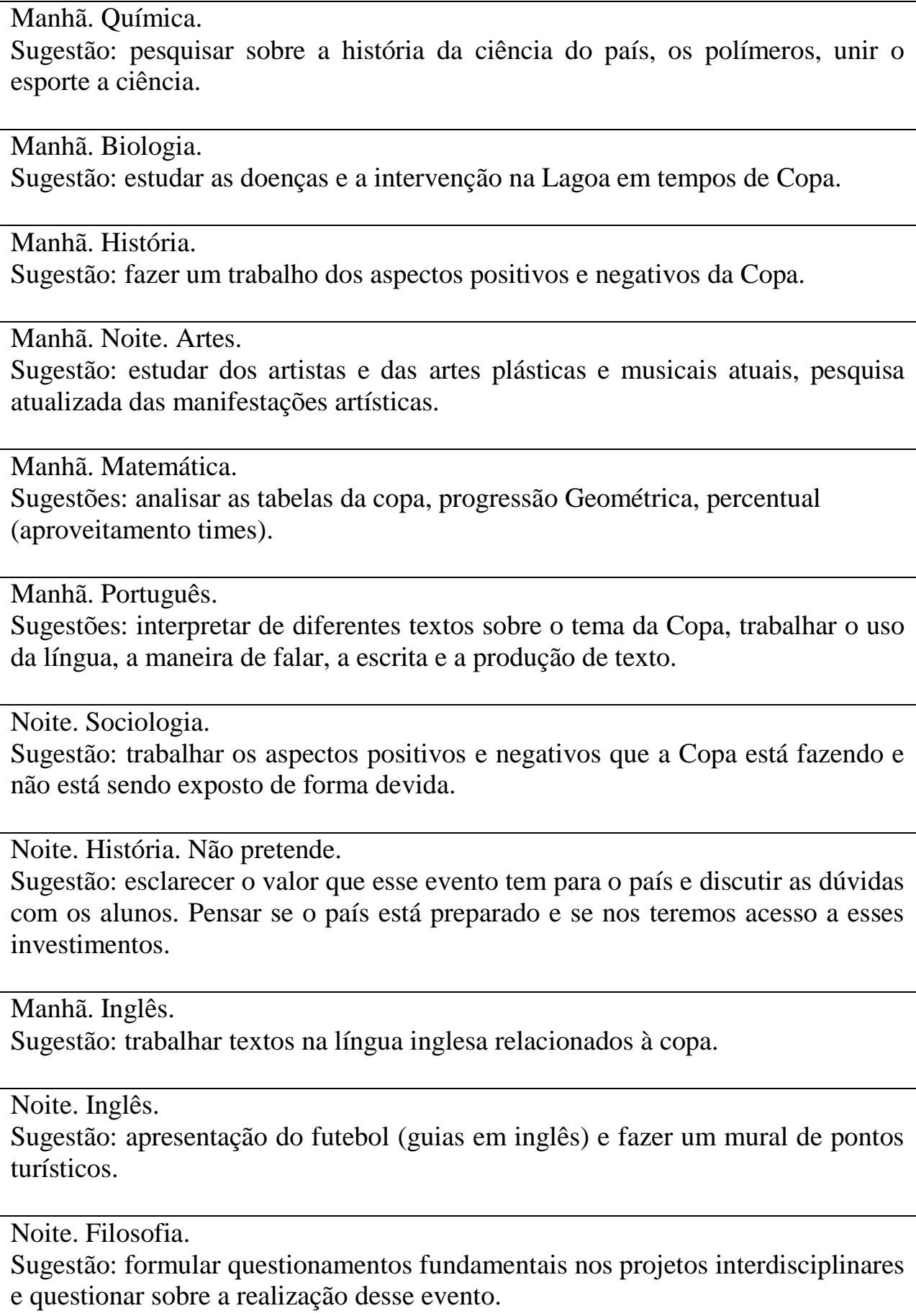

Noite. Filosofia.

Sugestão: formular questionamentos fundamentais nos projetos interdisciplinares e questionar sobre a realização desse evento. 


\section{Manhã. Educação Física.}

Sugestão: fazer um projeto interdisciplinar, falar "tudo" sobre os países além dos esportes.

Manhã. Geografia.

Sugestão: projeto com o objetivo de conhecer a Copa e como ela está acontecendo. Trabalho em três momentos: conhecimento, estratégias e intervenção.

\section{Manhã. Filosofia.}

Sugestão: fazer uma análise de forma reflexiva e crítica sobre o evento. "Não tem como ficar fora dessa discussão".

\section{Manhã. Física.}

Sugestões: investigar os conceitos de Física usados na Copa: energia, movimento, velocidade, mecânica, quântica para iniciantes. Inserir conceitos do século XXI em toda tecnologia da Copa.

\section{Manhã. Sociologia.}

Sugestão: análise social que gira em volta do evento e até do esporte.

Noite. Português.

Sugestão: pesquisar sobre questões das linguagens dos países da Copa e os costumes diferentes.

Noite. Geografia.

Sugestão: fazer uma exposição com material reciclado de cada país com indicativos sociais e analisar o contraste do Brasil com outros países.

Noite. Química.

Sugestão: estudar texto envolvendo o doping com a professora de português trabalho interdisciplinar. Outros exemplos: contusão, troca ou não de calor nos corpos.

Noite. Biologia.

Sugestão: estudar a proteção ao meio ambiente, produção de lixo produzido pela Copa, alimentos comercializados no evento e exercício físico.

Noite. Física.

Sugestão: trazer a vida real para a aula. Exemplo: tira-teima, queda-livre, velocidade da bola, questões de movimento.

Noite. Matemática.

Sugestão: estatística, probabilidade, sorteio, possíveis jogos.

Noite. Educação Física.

Sugestão: educar os alunos para a competição, saber perder e ganhar. Exemplo: campeonato envolvendo os países da Copa.

Fonte: Autores da pesquisa.

Todos os professores apresentaram sugestões referentes à participação ou contribuição de sua disciplina para elaboração de atividades ou projetos pedagógicos 
sobre Copa do Mundo FIFA Brasil 2014. Esse dado de 100\% indica que esse megaevento é multidisciplinar e potencialmente é um instrumento que pode ser utilizado como um meio e objeto de educação (MARCELLINO, 1998).

Todas as disciplinas foram contempladas com sugestões, reafirmando o caráter multidisciplinar desse megaevento de lazer para a elaboração de projetos pedagógicos. Também foram sugeridas atividades interdisciplinares, que segundo Fazenda (2008), assinala as trocas entre as especialidades pelo grau de integração real das disciplinas no interior de um mesmo projeto e exige-se que as disciplinas, em seu processo constante e de interpenetração trabalhem cada vez mais reciprocamente.

Em 2014, foi realizado um levantamento entre os professores a fim de verificar se os professores que responderam a pesquisa no ano anterior permaneceram nos cargos e com a intenção de realizar atividades ou projetos de educação relativos à Copa do Mundo da FIFA Brasil 2014.

Tabela 4 - Participação dos professores na pesquisa - consulta em 2014

\begin{tabular}{|l|c|c|}
\hline Participação & $\mathrm{N}^{\circ}$ de professores & $\%$ \\
\hline Participaram em 2013 e 2014 & 14 & 60,87 \\
\hline Participaram em 2014 & 9 & 39,13 \\
\hline Total & 23 & 100 \\
\hline
\end{tabular}

Fonte: Autores da pesquisa

Em 2014, entrevistei 23 (vinte e três) professores. Desse total, 14 (quatorze) participaram dos dois momentos da pesquisa. Esse dado indica que $60,87 \%$ continuaram com as turmas dos terceiros anos do ensino médio e 9 (nove) 39,13\% dos professores participaram somente da segunda etapa da pesquisa.

Em 2014 nenhum professor havia iniciado os trabalhos com a temática da Copa do Mundo da FIFA Brasil 2014. Porém, um terço dos docentes afirmou efetivamente a intenção de trabalhar com projetos referentes a essa temática. 
Tabela 5 - Intenção e desenvolvimento de projetos sobre a Copa - consulta em 2014

\begin{tabular}{|l|c|c|}
\hline & Quantidade & $\%$ \\
\hline $\begin{array}{l}\text { Intenção de desenvolver projeto em } \\
2014 .\end{array}$ & 2 & 34,78 \\
\hline $\begin{array}{l}\text { Não desenvolveu e não pretendiam } \\
\text { desenvolver projeto. }\end{array}$ & 15 & 65,22 \\
\hline Total & 23 & 100 \\
\hline
\end{tabular}

Fonte: Autores da pesquisa

Em 2014, do total de 23 (vinte e três) professores, 8 (oito) 34,78\% mostraram a intenção de elaborar projeto pedagógico referentes a Copa 2014; e 15 (quinze), equivalente a $65,22 \%$, não pretenderam desenvolver trabalho algum sobre $o$ megaevento.

Tabela 6 - Projetos das disciplinas relativos à Copa - consulta em 2014

Disciplina e atividade pedagógica

Português: pretende desenvolver nas suas aulas o levantamento de reportagens sobre a Copa e construção da escrita através de artigos de opinião.

Física: com a Educação Física - medidas da Física relacionadas à energia e à velocidade.

Educação Física: com a História e a Geografia - Copa do Mundo com o nome da escola. Está no plano de curso.

Sociologia: estava em busca de parceria - direito de manifestações, direito social, a Copa será referencial do trabalho.

Química: com a Biologia - doping - terceiro ano, foco no estudo da estrutura molecular dos compostos do doping.

Português: em fase de planejamento com produção e análise de texto sobre a Copa 2014.

Educação Física: com a Matemática e Geografia fará um torneio sobre a Copa.

Inglês: com Geografia e História: trabalhar os países da Copa cujos idioma oficial é o inglês. Dentro disso, explorar a questão de colonização (História) e territorial (Geografia), com o objetivo de conhecer o processo de colonização verificando a variação linguística.

Fonte: Autores da pesquisa 
Ao comparar as declarações dos 8 (oito) professores, 34,78\% que apresentaram a intenção de desenvolver algum projeto pedagógico em 2014, com os 16 (dezesseis), 69,56\% (categoria 1 e 2 da TAB. 2) que em 2013 pretendiam desenvolver alguma atividade pedagógica em 2014, verifica-se que ocorreu a redução significativa de 50\% da intenção de se trabalhar a Copa do Mundo da FIFA Brasil 2014 como projeto de educação.

Esses dados indicam que o megaevento que ocorreu no país constituiu em uma oportunidade especial pelo seu contexto e dimensão para a elaboração de projetos educacionais, sobretudo, pelo potencial pedagógico exemplificado pelos professores (TAB. 3), pela possibilidade de estabelecer diálogos com conteúdos referentes às disciplinas escolares e pela proximidade com o campo do lazer (MARCELLINO, 2008; ISAYAMA, 2010) ao demostrar o seu caráter multidisciplinar as possibilidades interdisciplinares e o potencial educativo.

\section{Considerações Finais}

Analisamos os documentos oficiais governamentais relativos à Copa do Mundo da FIFA Brasil 2014 e da escola. Constatamos que esses registros não trataram da educação enquanto possibilidade de ações pedagógicas na escola, tendo apresentado apenas preocupação em adequar o calendário escolar aos interesses do megaevento.

Além disso, não houve uma diretriz por parte da SEE-MG para as escolas, com o intuito de aproveitar o potencial pedagógico oferecido pela Copa do Mundo da FIFA Brasil 2014. Nessa mesma direção, a escola também não articulou o tema para ser trabalhado, o que gerou intenções pontuais que não foram documentadas. Dessa forma, acreditamos que este estudo mostrou que a ausência de uma diretriz, como a ocorrida nesse caso, fragilizou uma possibilidade de intervenção pedagógica que consideramos ter sido oportuna. Dito de outra forma parece ter ocorrido um efeito em cadeia. Não houve uma diretriz da SEE-MG, que por sua vez refletiu nos encaminhamentos da 
escola e no resultado com intenções isoladas de aproveitamento do evento por parte de alguns professores com ações pedagógicas pontuais.

Essa pesquisa afirma a multidisciplinaridade do lazer na escola e mostra que todas as disciplinas curriculares apresentam potencial para contribuir com a elaboração de projetos pedagógicos nessa área do conhecimento. A expansão do lazer como negócio somado a ampliação da oferta de produtos e serviços e o crescimento do consumo estimulado pelas mídias, demandam a intervenção da escola com o seu papel educativo para o entendimento da temática do lazer na sociedade, uma vez que o lazer, a educação e o consumo são temas centrais na formação dos estudantes pela escola, que requer a orientação dos consumidores como um papel da educação. Além disso, a escola precisa se ocupar da discussão do lazer, visto que ele é parte da cultura.

\section{REFERÊNCIAS}

BETTI, Mauro. Copa do mundo e jogos olímpicos: inversionalidade e transversalidades na cultura esportiva e na Educação Física escola. Motrivivência. v. 21,n. 32/33, p. 1627 Jun-Dez./2009.

BRACHT, V.; ALMEIDA, F. Q. Esporte, escola e a tensão que os megaeventos esportivos trazem para a Educação Física Escolar. Em Aberto, Brasília, v. 26, n. 89, p. 133-145, jan./jun. 2013.

BRACHT, V. Educação física escolar e lazer. In: WERNECK, Christiane Luce Gomes; Hélder Ferreira (Org.). Lazer, recreação e educação física. Belo Horizonte: Autêntica, 2003. v. 1, p.147 -172.

BRASIL. Lei $\mathbf{n}^{\mathbf{0}} \mathbf{1 2 . 6 6 3}$, de 05 de Junho de 2012. Dispõe sobre as medidas relativas à Copa das Confederações FIFA 2013, à Copa do Mundo FIFA 2014 e à Jornada Mundial da Juventude - 2013. Disponível em http://www.planalto.gov.br/ccivil_03/_ato20112014/2012/Lei/L12663.htm. Acesso em: 17 jan. 2014.

BRASIL. Lei $\mathbf{n}^{0}$ 9.394, de 20 de dezembro de 1996. Estabelece as diretrizes e bases da educação nacional. Diário Oficial Federativa do Brasil, Brasília, DF, n.248, 23 dez. 1996.

CAMPOS, P. A. F. Mulheres torcedoras do Cruzeiro Esporte Clube presentes no Mineirão. 142f. Dissertação (Mestrado Interdisciplinar em Lazer) - Escola de Educação 
Física, Fisioterapia e Terapia Ocupacional, Universidade Federal de Minas Gerais, Belo Horizonte, 2010.

CANDAU, Vera Maria. Construir ecossistemas educativos - Reinventar a Escola. In: Reinventar a escola. 5. ed. Petrópolis: Vozes, 2007. 259p.

DAÓLIO, Jocimar Educação física escolar e megaeventos esportivos: desafios e possibilidade. Revista Kinesis, RS, v. 31, n. 1, p. 125-137, jan./jun. 2013.

FAZENDA, I. C. A. O que é Interdisciplinaridade? São Paulo: Cortez, 2008.

FORQUIN, Jean-Claude. Escola e Cultura: as bases sociais e epistemológicas do conhecimento escolar. Tradução de Guacira Lopes Loro. Porto Alegre: Artes Médicas, 1993. 205p.

ISAYAMA, H. F. Formação profissional no âmbito do lazer: desafios e perspectivas. In: ISAYAMA, H. F. (Org.). Lazer em Estudo: currículo e formação profissional. Campinas: Papirus, 2010, p. 09- 26.

LIBÂNEO, José Carlos; OLIVEIRA, João Ferreira de; TOSCHI, Mirza Seabra. Educação escolar: políticas, estrutura e organização. 6. ed. São Paulo: Cortez, 2008. 407 p.

MACHADO, R. P. T.; RUBIO, K. Legados do esporte: atleta, cultura e educação. In: MARCELlinO, N. C. (Org.). Legados de Megaeventos Esportivos. Campinas: Papirus, 2013.

MADRUGA, Djan. Megaeventos Esportivos como Gestão de Custos Oportunidades. In: RODRIGUES, R. P.; PINTO, L.M.; DACOSTA, L. (Org.). Legados de megaeventos esportivos. Brasília: Ministério do Esporte, 2008.p. 59-64.

MAGNANI, José Guilherme Cantor. Lazer, um campo interdisciplinar de pesquisa. IN: BRUHNS, Heloisa Torini . E GUTIERREZ Gustavo Luiz (Org.). O corpo e o Lúdico: Ciclo de debates "lazer e motricidade". Campinas: Autores Associados, 2000. p.19-34.

MARCELLINO, N. C. Megaeventos: perspectivas para o lazer. In: MARCELLINO, N. C. (Org.). Legados de Megaeventos Esportivos. Campinas: Papirus, 2013.

A relação teoria e prática na formação profissional em lazer. In: ISAYAMA, H. F. (Org.). Lazer em Estudo: currículo e formação profissional. Campinas: Papirus, 2010, p. 59- 86.

Alínea, 2008.

Lazer e Educação. 4. ed. Campinas: Papirus, 1998.

MASCARENHAS, Fernando. Políticas sociais, lazer e educação: apontamentos para uma pedagogia crítica. Revista Corpo consciência, Santo André, v. 11, n. 2, p. 02-09, jul/dez, 2007.

MINAS GERAIS. Secretária de Estado de Educação. Estabelece, para a Rede Pública Estadual de Educação Básica, o calendário escolar para o ano de 2014. Resolução n. 2368, de 09 de agosto de 2013. Disponível em <www.educação.mg.br/images/documentos/2368-13-r.pdf>. Acesso em: 15 fev. 2014. 
NICÁCIO, L.G. O torcer no futebol como possibilidade de lazer e a educação física escolar. In: SILVA. S.R. da. DEBORTOLI, J.A. de O. SILVA, T.F.da (Org.). O futebol nas Gerais. Belo Horizonte: Editora UFMG, 2012. p. 187- 202.

PIRES, L. S.; BAPTISTA, L. F. S. Portugal. Megaeventos e o Desenvolvimento Urbano e Regional: uma análise das especificidades e impactos proveniente dos jogos olímpicos e um panorama para a cidade do Rio de Janeiro. Revista Brasileira de Estudos Urbanos e Regionais, Anpur. 2013. Disponível em: <http://www.anpur.org.br/revista/rbeur/index.php/anais/article/viewFile/4209/4080>. Acesso em: 13 mar. 2014.

RATTON, José Luiz. Megaeventos esportivos, violência e pânico moral: breves considerações sociológicas. Coletiva. Número 08, abr/maio/jun 2012. Disponível em: http://www.coletiva.org/site/index.php?option=com_k2\&view=item\&layout=item\&id= 99\&Itemid=76\&idrev=11. Acesso em: 30 dez. 2012.

REIS, H. H. B. Futebol e sociedade: as manifestações da torcida. 1998. Tese (Doutorado em Educação Física) - Faculdade de Educação Física, Universidade Estadual de Campinas, Campinas, 1998.

RUBIO, K. Os Jogos Olímpicos e a Transformação das Cidades: Os Custos Sociais de um Megaevento. Revista Electrónica de Geografía y Ciencias Sociales, Universidad de Barcelona, v. IX, n. 194 (85), 2005. Disponível em: <http://www.ub.edu/geocrit/sn/sn-194-85.htm>. Acesso em: 13 mar. 2014.

SILVA. C. L. da. Legados de megaeventos esportivos: perdas e ganhos para a educação física escolar. MARCELLINO N.C. (Org.). Legados de megaeventos esportivos. Campinas: Papirus, 2013.

SILVA, R. S. da; CAMPOS, P. A.F. Futebol e Educação Física na escola: possibilidades de uma relação educativa. Ciência e cultura. v. 66, n. 2, São Paulo. June 2014. Disponível em: http://cienciaecultura.bvs.br/scielo.php?pid=S00067252014000200015\&script=sci_arttext Acesso em: 07 jul. 2014.

SILVA, S. R.; SOUZA NETO, G. J.; CAMPOS, P. A. F. Lazer, torcidas e futebol. In: ISAYAMA, H. F.; SILVA, S. R. Estudos do Lazer: um panorama. Rio de Janeiro, Apicuri, 2011.p. 111-123.

\section{Endereço dos Autores:}

Amarildo da Silva Araújo

Silvio Ricardo da Silva

EEFFTO/UFMG

Av. Pres. Antônio Carlos 6627 - Pampulha

Belo Horizonte - MG - 31270-901

Endereço Eletrônico: prof.srs@gmail.com 